\title{
La construcción jurisprudencial de la Europa de los valores: jueces, criterios ético-políticos y razonamiento jurídico en torno al inicio de la vida
}

\author{
Bajo la coordinación de \\ Josep $\mathrm{M}^{\mathrm{a}}$ Castellà Andreu \\ Universidad de Barcelona \\ Carlos Vidal Prado \\ Universidad Nacional de Educación a Distancia
}

\section{Presentación}

El pasado 30 de marzo de 2012 se celebró en Madrid el VI Encuentro hispano italiano de constitucionalistas, que se viene celebrando con periodicidad anual a partir del que tuvo lugar en Turín en 2006, teniendo como sede, alternativamente, una ciudad italiana y otra española.

De estos encuentros se han derivado publicaciones de muchos de los participantes. Merece destacarse la obra colectiva que coordinó Antonio D'Aloia Il Diritto e la vita. Un diálogo italo-spagnolo su aborto ed autanasia, publicado por Jovene editore en Nápoles, en 2011, y que es el fruto del seminario celebrado en esa misma ciudad.

El último de estos encuentros tuvo lugar en Madrid, en la Real Academia de Jurisprudencia y Legislación, y en él se abordó la cuestión de "La construcción jurisprudencial de la Europa de los valores: jueces, criterios ético-políticos y razonamiento jurídico en torno al inicio de la vida". Gracias a la oportunidad que nos brinda la Revista Estudios de Deusto, y especialmente su secretario, Luis Gordillo, podemos ofrecer ahora algunas contribuciones de las expuestas en dicho seminario. Se trata de las dos ponencias (de los profesores Emanuele Rossi y Pablo Nuevo) y de los textos de varias de las intervenciones que tuvieron lugar durante la reunión académica, de ahí la extensión y tono de estos escritos. Confiamos en que pueda resultar interesante la lectura de dichas aportaciones y contribuir al debate abierto en Europa sobre la temática. 